\title{
COGNITIVE PERFORMANCE AFTER CARDIAC OPERATION: IMPLICATIONS OF REGRESSION TOWARD THE MEAN
}

S. M. Browne, MBBSa

P. W. Halligan, $\mathrm{PhD}^{\mathrm{b}}$

D. T. Wade, $\mathrm{MD}^{\mathrm{c}}$

D. P. Taggart, MD, Hons FRCS ${ }^{\mathrm{a}}$
Objective: The purpose of this study was to assess the influence of regression toward the mean on different definitions of cognitive dysfunction after coronary artery bypass graft operation. Methods: A total of 120 patients who underwent nonemergency coronary bypass operation and who were involved in a randomized trial of an anti-inflammatory agent were assessed prospectively with a battery of 10 psychometric tests covering a variety of cognitive domains. The battery was administered before the operation and 5 days and 3 months after the operation. Data from 2 representative tests, the Rey Auditory Verbal Learning Test and the Trail Making Test (part A), were used. The influence of regression toward the mean on 3 commonly used single-case definitions of cognitive impairment (1 SD method; one-half SD method; $20 \%$ method) was analyzed. Results: Group mean performance deteriorated on the Rey Auditory Verbal Learning Test at the discharge assessment $(P<.001)$ and remained below baseline at 3 months $(P=.03)$. Mean performance on the Trail Making Test (part A) showed a near-significant decline at discharge $(P=.06)$, followed by improvement at 3 months $(P<.01)$. Regression toward the mean was demonstrated on both tests by classifying the preoperative scores into low, moderate, and high-performance categories. Applying the different definitions of dysfunction resulted in substantially larger numbers of patients in the high-performance group being classified as impaired. Conclusion: Single-case definitions of cognitive dysfunction are influenced strongly by regression toward the mean. Disproportionate numbers of high-baseline performers are classified as impaired, thereby questioning the validity of established definitions. Group mean analysis with controls is potentially the most reliable method for detecting real change or differences. (J Thorac Cardiovasc Surg 1999;117:481-5)
T he assessment of cognition before and after cardiac operation is now used extensively as a measure of surgical outcome, after reports a decade ago that suggested "intellectual dysfunction" could affect as many as

From The Oxford Heart Centre, John Radcliffe Hospital, Headington, ${ }^{\mathrm{a}}$ the Department of Experimental Psychology, ${ }^{\text {b }}$ Rivermead Rehabilitation Centre, and Rivermead Rehabilitation Centre, ${ }^{\mathrm{c}}$ Oxford, United Kingdom.

Supported by British Biotech Pharmaceuticals Limited.

Received for publication June 5, 1998; revisions requested Sept 17, 1998; revisions received Oct 15, 1998; accepted for publication Oct 19, 1998.

Address for reprints: Peter Halligan, PhD, Department of Experimental Psychology, Rivermead Rehabilitation Centre, Abingdon Road, Oxford OX1 4XD, United Kingdom.

Copyright (C) 1999 by Mosby, Inc.

$0022-5223 / 99 \$ 8.00+0 \quad \mathbf{1 2 / 1 / 9 5 2 9 3}$
$80 \%$ of patients. ${ }^{1,2}$ The incidence of cognitive decline after cardiac operation has been subsequently used to compare outcomes in different centers, to assess the efficacy of neuroprotective drugs, and to improve perfusion techniques and surgical management.,6 Despite the increasing application and importance of such neuropsychologic tests as measures of cognitive impairment, little attention has been focused on the limitations of the different criteria used to define impairment.

One of the simplest methods of defining cognitive impairment uses a predetermined deterioration threshold to establish whether an individual's postoperative performance has significantly declined. This singlecase analysis technique uses each patient as his/her own control and was recently endorsed at an international consensus meeting as the preferred method of defining 
cognitive impairment. ${ }^{7}$ Several methods of determining the deterioration threshold are now commonly used, including the use of the group standard deviation (SD) or one-half SD and the percentage change. ${ }^{8}$

The problem with these and similar techniques, however, is that they are susceptible to the potential bias of regression toward the mean (RTM). RTM is the statistical phenomenon whereby extreme baseline scores tend to become less extreme after repeated examinations, even though "true" change has not occurred. ${ }^{9} \mathrm{~A}$ simple example of RTM would be in repeated measurements of blood pressure whereby on some occasions, by chance alone, the blood pressure may be higher or lower than normal. RTM states that unusually high or low blood pressures are by definition uncommon events and that the chance of a repetition of high or low blood pressure twice in a row is unlikely. In fact, by chance alone or random fluctuations, the next measurement is likely to be nearer the average value.

The effect of RTM is present wherever there is an intrasubject variation on a repeated test ${ }^{10}$ and will therefore be an inevitable feature of cognitive assessment. Examples of misinterpretation that result from a failure to recognize RTM are common in the literature, ${ }^{11,12}$ but the issue has not been addressed in relation to cognitive change after cardiac operations.

This study demonstrates the influence of RTM and the implications for the different definitions of impairment currently used, with data from a large group of patients who underwent coronary artery bypass graft operation. The results of the study provide a simple, but nevertheless salutary, illustration of the need to consider the effects of RTM. Possible solutions for countering the effects of RTM are proposed.

\section{Methods}

One hundred twenty patients who underwent nonemergency coronary artery bypass graft operation completed serial assessment on a battery of 10 standard psychometric tests. The patients, who had provided written informed consent, were part of a double-blind trial investigating the efficacy of a new anti-inflammatory drug (placebo, low dose, and high dose). In this study, the patients were drawn approximately equally from the 3 study arms. Patients were examined before the operation ( 1 day before the operation), before hospital discharge (mean, 5.5 days after the operation; SD, 1.3 days), and again 3 months after the operation (mean, 96 days; SD, 8.9 days). The test battery was administered by a single examiner (S.M.B.) and included the following tests:

National Adult Reading Test ${ }^{13}$

Short Orientation-Memory-Concentration Test ${ }^{14}$

Rey Auditory Verbal Learning Test ${ }^{15}$

Trail Making Test (part A) ${ }^{15}$
Trail Making Test (part B) ${ }^{15}$

Adult Memory Information Processing Battery (test A) ${ }^{16}$

Nine Hole Peg Board Test ${ }^{14}$

CFL Word Generation Test ${ }^{15}$

Digit Span Test ${ }^{15}$

Bell Cancellation Test ${ }^{17}$

Although data from any of the tests are sufficient to demonstrate RTM, for simplicity we have chosen to analyze the data from 2 tests: the Delayed Recall component of the Rey Auditory Verbal Learning Test (RAVLT) and the Trail Making Test (part A; TMTA). These are 2 of the 4 core tests recommended for inclusion in psychometric testing at the consensus conference in $1994 .{ }^{18}$ Briefly, the RAVLT is a test of verbal memory that allows assessment of immediate and delayed recall. ${ }^{15}$ The Delayed Recall component is the total of 2 attempts (after 2-minute and 25-minute delays) at recalling as many words as possible from a list of 15 words, previously read to the subject 5 times. The maximum possible score is 30 and the minimum is 0 . To minimize practice effects, a different list of words is used at each time point. The second test, the TMTA, is a test of visuospatial and psychomotor performance. ${ }^{15}$ The subject is required to connect 25 numbered circles spread across a page in correct ascending order. The measured variable is the time taken to complete the task. Lower scores represent superior performance. The standard form was used at all 3 time-points.

The following 3 definitions of impairment were used to calculate frequency of decline within each of the 2 tests and, subsequently, to analyze for evidence of RTM. All these definitions of impairment have been used previously in the cardiac literature to measure significant change.

1. SD method: postoperative decline in a subject's performance of more than $1 \mathrm{SD}$ of the group's scores before the operation..$^{1-4}$

2. One-half SD method: decline of one-half SD from the score before the operation. ${ }^{20}$

3. Twenty-percent method: decline of more than $20 \%$ of the subject's score before the operation. ${ }^{19}$

Statistical analysis of change scores was performed with paired $t$ tests (for normally distributed data) and Wilcoxon signed rank tests (for non-normally distributed data). Individual change scores were calculated by subtracting the score achieved before the operation from the score achieved after the operation (at discharge and 3 months).

\section{Results}

Table I provides the means, SDs, 95\% confidence intervals, median, interquartile range, and range for the RAVLT and TMTA tests in all 120 patients at the 3 time points. It should be noted that for RAVLT assessment higher scores indicate better performance, whereas for TMTA lower scores indicate better performance. With the RAVLT, it can be seen that the group as a whole deteriorated significantly at the discharge assessment, 
Table I. Group mean (SD and 95\% CI), median interquartile range (IQR), and range for the 3 assessment points on the RAVLT and TMTA

\begin{tabular}{|c|c|c|c|}
\hline \multirow[b]{2}{*}{ Psychometric test } & \multicolumn{3}{|c|}{ Assessment points } \\
\hline & $\begin{array}{c}\text { Before } \\
\text { operation }\end{array}$ & Discharge & $\begin{array}{l}\text { Three } \\
\text { months }\end{array}$ \\
\hline \multicolumn{4}{|l|}{$\operatorname{RAVLT}^{*}(\mathrm{n}=120)$} \\
\hline Mean & $14.1(5.1)$ & $11.7(5.2)^{\dagger}$ & $13.2(5.4)^{\ddagger}$ \\
\hline $95 \% \mathrm{CI}$ & $13.1-15.0$ & $10.7-12.6$ & $12.3-14.2$ \\
\hline Median & 14 & 11 & 13 \\
\hline $\mathrm{IQR}$ & $10-17$ & $8-15$ & $9-17$ \\
\hline \multicolumn{4}{|l|}{$\mathrm{TMTA}^{\S}(\mathrm{n}=120)$} \\
\hline Mean & $36.3(12.7)$ & $37.8(13.3)$ & $33.9(10.6) \ddagger$ \\
\hline $95 \% \mathrm{CI}$ & $34.0-38.6$ & $35.4-40.2$ & $32.0-35.8$ \\
\hline Median & 35.5 & 36 & 31 \\
\hline IQR & $28-41$ & $29-41$ & $27-39$ \\
\hline
\end{tabular}

Note: High scores on the RAVLT and low scores on TMTA indicate better performance.

*Paired $t$ tests (change from preoperative scores).

${ }^{\dagger} P<.001$.

$\stackrel{\$}{\sharp}<.05$.

\$Positively skewed distribution; Wilcoxon signed rank test used (change from preoperative scores).

with the mean declining by 2.4 points (95\% CI, 1.6$3.3 ; P<.001)$. Although group performance subsequently improved at 3 months, it remained significantly lower than baseline (mean decline, 0.9; 95\% CI, 0.1-0.6: $P=.03$ ). For the TMTA, the group declined at discharge, with the mean time slowing by 1.5 seconds (95\% CI, -0.1 to 3.1: $P=.06$ ). At 3 months, the group's mean time significantly improved by 2.4 seconds ( $95 \%$ CI, 0.6-4.2: $P<.001$ ) from baseline.

To demonstrate the effects of RTM, the preoperative results from the 2 tests were each divided arbitrarily into 3 equal performance categories (low, moderate, and high) as shown in Tables II and III. Subjects who scored less than 12 in the RAVLT were classified as low performers $(\mathrm{n}=35$ subjects); those subjects who scored 12 to 16 were rated moderate ( $\mathrm{n}=51$ subjects), and those subjects who scored 17 or more were rated high ( $\mathrm{n}=34$ subjects). For the TMTA, times of $40 \mathrm{sec}-$ onds or more were classified low ( $\mathrm{n}=36$ subjects); times of 30 to 39 seconds (inclusive) were classified moderate ( $\mathrm{n}=50$ subjects), and times of less than 30 seconds were rated high $(\mathrm{n}=34$ subjects). Table II shows the mean scores over time for the 3 performance categories within the RAVLT, and Table III shows the mean scores for the TMTA.

It is clear from Tables II and III that each performance group has a different pattern of scores over time. For example, on the RAVLT, the high-performance cat-
Table II. Mean scores (SD and 95\% CI), medians, $I Q R$, and range for each performance category at 3 assessment points on the RAVLT

\begin{tabular}{llll}
\hline & \multicolumn{3}{c}{ Assessment points } \\
\cline { 2 - 4 } $\begin{array}{l}\text { Performance } \\
\text { category }\end{array}$ & \multicolumn{3}{c}{$\begin{array}{c}\text { Three } \\
\text { months }\end{array}$} \\
\hline Low $(\mathrm{n}=35)$ & & & \\
Mean & $8.1(2.0)$ & $8.6(4.0)$ & $8.7(3.5)$ \\
$95 \%$ CI & $7.4-8.8$ & $7.2-10.0$ & $7.5-10.0$ \\
Median & 8 & 8 & 9 \\
IQR & $7-9$ & $5-12$ & $6-11$ \\
Moderate $(\mathrm{n}=51)$ & & & \\
Mean & $13.9(1.4)$ & $11.1(4.1)^{*}$ & $13.5(4.2)$ \\
$95 \%$ CI & $13.5-14.3$ & $9.9-12.3$ & $12.3-14.7$ \\
Median & 14 & 11 & 13 \\
IQR & $13-15$ & $8-14$ & $10-17$ \\
High (n = 34) & & & \\
Mean & $20.4(2.9)$ & $15.7(5.2)^{*}$ & $17.5(5.0)^{*}$ \\
95\% CI & $19.4-21.4$ & $13.8-17.5$ & $15.7-19.2$ \\
Median & 19 & 16 & 18 \\
IQR & $19-22$ & $12-20$ & $14-20$ \\
\hline
\end{tabular}

Note: High score indicates better performance; Wilcoxon signed rank test (change from preoperative scores).

${ }^{*} P<.001$.

Table III. Mean scores (SD and 95\% CI), medians, $I Q R$, and range for each performance category at 3 assessment points on the TMTA

\begin{tabular}{llll}
\hline \multicolumn{3}{c}{ Assessment points } \\
\hline $\begin{array}{l}\text { Performance } \\
\text { category }\end{array}$ & Preoperative & Discharge & $\begin{array}{l}\text { Three } \\
\text { months }\end{array}$ \\
\hline Low (n = 36) & & & \\
Mean & $50.3 .1(12.7)$ & $48.6(15.0)$ & $40.3(12.0)^{*}$ \\
95\% CI & $45.9-54.6$ & $43.5-53.7$ & $36.3-44.4$ \\
Median & 44.5 & 45 & 37.5 \\
IQR & $42-57$ & $37-60$ & $29-48$ \\
Moderate (n=50) & & & \\
Mean & $35.0(2.9)$ & $36.8(8.9)$ & $34.1(8.8)$ \\
95\% CI & $34.2-35.8$ & $34.3-39.3$ & $31.6-36.6$ \\
Median & 35 & 36.5 & 32 \\
IQR & $32-37$ & $30-42$ & $28-38.5$ \\
High (n = 34) & & & \\
Mean & $23.4(3.1)$ & $27.9(6.9)^{\dagger}$ & $26.7(6.0)^{\dagger}$ \\
95\% CI & $22.3-24.5$ & $25.4-30.3$ & $24.6-28.8$ \\
Median & 23.5 & 27.5 & 26.5 \\
IQR & $21-26$ & $23-31$ & $22-30$ \\
\hline
\end{tabular}

Note: High score indicate worse performance; Wilcoxon signed rank test (change from preoperative scores).

${ }^{*} P<.0001$.

${ }^{\dagger} P<.001$.

egory showed significant deterioration from the baseline at both the early and late postoperative assessments. The moderate performers showed significant 
Table IV. No. of patients whose scores declined after operation (entire group and performance categories) on the RAVLT and the TMTA, with 3 different definitions of cognitive impairment

\begin{tabular}{|c|c|c|c|c|c|c|}
\hline \multirow[b]{3}{*}{ Performance category } & \multicolumn{6}{|c|}{ Definition of cognitive impairment } \\
\hline & \multicolumn{2}{|c|}{$1 S D$ method } & \multicolumn{2}{|c|}{ 1/2 SD method } & \multicolumn{2}{|c|}{$20 \%$ Method } \\
\hline & Discharge (\%) & Three months (\%) & Discharge (\%) & Three months (\%) & Discharge (\%) & Three months (\%) \\
\hline RAVLT $(\mathrm{n}=120)$ & $28(23)$ & $19(16)$ & $61(51)$ & $39(33)$ & $58(48)$ & $37(31)$ \\
\hline Low $(\mathrm{n}=35)$ & $2(6)$ & $2(6)$ & $9(26)$ & $8(23)$ & $12(34)$ & $10(29)$ \\
\hline Moderate $(\mathrm{n}=51)$ & $13(25)$ & $8(16)$ & $28(55)$ & $14(27)$ & $28(55)$ & $14(27)$ \\
\hline $\operatorname{High}(\mathrm{n}=34)$ & $13(38)$ & $9(26)$ & $24(71)$ & $17(50)$ & $18(53)$ & $13(38)$ \\
\hline $\operatorname{TMTA}(\mathrm{n}=120)$ & $15(13)$ & $8(7)$ & $30(25)$ & $19(16)$ & $31(26)$ & $25(21)$ \\
\hline Low $(n=36)$ & $4(11)$ & $0(0)$ & $6(17)$ & $3(8)$ & $5(14)$ & $1(3)$ \\
\hline Moderate $(\mathrm{n}=50)$ & $6(12)$ & $6(12)$ & $13(26)$ & $9(18)$ & $13(26)$ & $9(18)$ \\
\hline $\operatorname{High}(\mathrm{n}=34)$ & $5(15)$ & $2(6)$ & $11(32)$ & $7(21)$ & $13(38)$ & $15(44)$ \\
\hline
\end{tabular}

early postoperative decline. The low performers category showed nonsignificant change. Low baseline performers on the TMTA showed significant improvement at 3 months, whereas the high performers again showed significant deterioration from baseline at both postoperative assessments. These 2 examples show that the high performers tend to perform less well as a group compared with their baseline scores, whereas the low baseline performers have a tendency for improvement. In other words, they are examples of RTM.

Table IV shows the rate of cognitive decline calculated for each of the 2 tests according to each of the previously described definitions. Additionally, frequency of cognitive decline for each performance category has been provided. In both tests, a disproportionately large number of subjects from the high-performance categories are classified as declined, in comparison with the generally small percentage of subjects classified as declined in the low-performance categories. For example, on the RAVLT, the SD method classified 23\% of the entire group as impaired, whereas $38 \%$ of the high performers were similarly classified. Although floor effects can influence these frequencies, ${ }^{21}$ the major reason for these discrepancies is RTM. This is emphasized by equally diverse rates of decline within performance categories on the TMTA, a test that is not affected by floor effects.

Although results from only the RAVLT and the TMTA have been analyzed in detail in this article, similar RTM effects were seen on the other tests in the battery. The preoperative mean scores of the patients classified as impaired (by the SD method at each time point) were consistently better than the preoperative mean scores of the entire group, indicating that on each test it is high-baseline performers who are disproportionately classified as declined.

\section{Discussion}

Cognitive performances after cardiac operations may be influenced by several important factors. First, scores may be affected by the cardiac operation itself. Our results provide typical examples of this postoperative cognitive change. Second, the effects of practice may influence results, with group performances often improving when psychometric tests are administered repeatedly. ${ }^{22}$ This probably explains the improvement we found in the group's mean time on the TMTA at the 3-month assessment. Practice effects can be minimized by the use of alternative forms and long follow-up intervals ${ }^{15}$ or controlled by a comparison group that undergoes the same assessments at the same time points. ${ }^{21} \mathrm{~A}$ third factor that can significantly influence cognitive test scores is the phenomenon of RTM. ${ }^{9}$

In contrast to other fields of research, ${ }^{9}$ RTM has received minimal attention in the cardiac surgical literature. ${ }^{21}$ This is surprising, because failure to control for RTM can lead to devastatingly erroneous conclusions. ${ }^{9}$ It is evident in our article that single-case definitions are particularly vulnerable to its effects, with greater proportions of high-baseline performers being classified as impaired. There is no a priori reason why cardiac operations should disproportionately affect cognitive function in those subjects with high baseline scores. Such a situation is unavoidable by categorizing changes in performance as either "declined/not declined" because high-baseline performers will tend to regress downward even in the absence of real change. A smaller true decline is all that is required for these subjects to pass an impaired threshold. The converse situation for low-baseline performers results in fewer subjects being classified as impaired, because their scores would tend to improve because of RTM, thereby requiring a much larger true decline to pass the cut- 
off. Therefore definitions of impairment that only focus attention on declining scores will always bias results by including disproportionate numbers of high-baseline performers. To rely on these results clearly risks misinterpretation.

To overcome the influence of RTM on cognitive performance scores, multiple data points are required. ${ }^{11}$ Within a single-case design, this would involve the performance of multiple preoperative cognitive assessments that could be averaged to obtain a subject's "true" baseline level. Similar multiple assessments might be required in the postoperative period when performance was deemed to be stable, again to establish a reliable level of function. It has been suggested that 2 or 3 assessments at baseline can minimize much of the effect of RTM. ${ }^{11}$ The difficulties of performing such a large number of assessments, however, in addition to the greater likelihood of practice effects, makes this option impractical.

A more convenient alternative that overcomes the problem of RTM involves the use of group means. ${ }^{11}$ Group mean analysis allows the application of parametric statistical methods that are free from the influence of RTM. Proponents of single-case designs, however, argue that this approach fails to account for the effects of practice, because overall group mean improvement can mask individuals who have deteriorated. ${ }^{21}$ This criticism is valid only in the absence of a suitable age-matched control group. Such a group would allow for the control of both RTM and practice effects because both of these would be expected to occur equally in both groups.

In conclusion, the phenomenon of RTM should be recognized as a significant cause of variation within postoperative cognition scores. Results from studies that fail to appreciate its influence should be viewed with caution. The use of group mean data with appropriate control mean data should be the method of choice.

We thank the patients who took part in this study for their interest and enthusiasm and the staff at the Oxford Heart Centre for their support, with a special mention to Tessa Longney for the assistance she provided in patient recruitment.

\section{REFERENCES}

1. Shaw PJ, Bates D, Cartlidge NEF, et al. Early intellectual dysfunction following coronary bypass surgery. QJM 1986;225:59-68.

2. Newman S, Smith P, Treasure T, Joseph P, Ell P, Harrison M. Acute neuropsychological consequences of coronary artery bypass surgery. Curr Psychol Res Rev 1987;6:115-24.
3. Patel RL, Turtle MR, Chambers DJ, James DN, Newman S, Venn GE. Alpha-stat acid-base regulation during cardiopulmonary bypass improves neuropsychologic outcome in patients undergoing coronary artery bypass grafting. J Thorac Cardiovasc Surg 1996;111:1267-79.

4. Pugsley W, Klinger L, Paschalis C, Treasure T, Harrison M, Newman S. The impact of microemboli during cardiopulmonary bypass on neuropsychological functioning. Stroke 1994;25:13939.

5. Grieco G, d'Hollosy M, Culliford AT, Jonas S. Evaluating neuroprotective agents for clinical anti-ischemic benefit using neurological and neuropsychological changes after cardiac surgery under cardiopulmonary bypass. Stroke 1996;27:858-74.

6. Murkin JM. Anesthesia, the brain and cardiopulmonary bypass. Ann Thorac Surg 1993;56:1461-3.

7. Murkin JM, Stump DA, Blumenthal JA, McKhann G. Defining dysfunction: group means versus incidence analysis-a statement of consensus. Ann Thorac Surg 1997;64:904-5.

8. Mahanna EP, Blumenthal JA, White WD, et al. Defining neuropsychological dysfunction after coronary artery bypass grafting. Ann Thorac Surg 1996;61:1342-7.

9. Kim H. Regression of lateral asymmetry scores towards the mean. Cortex 1994;30:331-41.

10. Bland JM, Altman DG. Regression towards the mean. BMJ 1994; 308:1499.

11. Yudkin PL, Stratton IM. How to deal with regression to the mean in intervention studies. Lancet 1996;347:41-3.

12. Bland JM, Altman DG. Some examples of regression towards the mean. BMJ 1994;309:780.

13. Nelson HE. National Adult Reading Test: test manual. Windsor [UK]: NFER-Nelson; 1982.

14. Wade DT. Measurement in neurological rehabilitation. Oxford: Oxford University Press; 1992.

15. Lezak MD. Neuropsychological assessment. New York: Oxford University Press; 1976.

16. Coughlan AK, Hollows SE. The Adult Memory and Information Processing Battery: test manual. Leeds [UK]: AK Coughlan; 1985.

17. Gauthier L, Dehaut F, Joanette Y. The Bells Test: a quantitative and qualitative test for visual neglect. Int J Clin Neuropsychol 1989;11:49-54.

18. Murkin JM, Newman SP, Stump DA, Blumenthal JA. Statement of consensus on assessment of neurobehavioral outcomes after cardiac surgery. Ann Thorac Surg 1995;59:1289-95.

19. Stump DA, Newman SP, Coker LH, Wallenhaupt SL, Roy RC. The effect of age on neurologic outcome after cardiac surgery. Anesth Analg 1992;74(suppl):S310.

20. McKhann GM, Goldsborough MA, Borowicz LM, et al. Cognitive outcome after coronary artery bypass: a one-year prospective study. Ann Thorac Surg 1997;63:510-5.

21. Newman SP. Analysis and interpretation of neuropsychologic tests in cardiac surgery. Ann Thorac Surg 1995;59:1351-5.

22. Feinstein A, Brown R, Ron M. Effects of practice of serial tests of attention in healthy subjects. J Clin Exp Neuropsychol 1994; $16: 436-47$. 